\title{
Formulations of Controlled Atmosphere Agents for Packaged Foods
}

\author{
Wan-Hwa Huang, Cheng-Kuang Hsu, and Been-Huang Chiang* \\ Graduate I nstitute of Food Science and Technology, National Taiwan University, \\ 59, Lane 144, Keelung Road, Sec. 4, Taipei, Taiwan, ROC
}

\begin{abstract}
Four food grade additives-sodium ascorbate, sodium bicarbonate, sodium carbonate-10-hydrate, and ferrous sulfate-7-hydrate-were selected as the basic ingredients to formulate the controlled atmosphere agents which could effectively remove oxygen and release carbon dioxide. The mathematical models giving the relationships between the formulations and the responses (oxygen and carbon dioxide contents) were developed using response surface methodology (RSM). Within 8-24 $\mathrm{h}$, the oxygen and carbon dioxide contents of all tested formulations could reach constant levels, in the ranges of $2-9 \%$ and $0-41 \%$, respectively. These formulations were considered to be effective, safe, and easy to prepare and could be applied to wide varieties of food products.
\end{abstract}

Keywords: Controlled atmosphereagent; formulation; responsesurfacemethodology; food packaging

\section{INTRODUCTION}

The use of controlled atmosphere packaging (CAP) techniques in the food industry has gained attention worldwide due to increased consumer demand for highquality fresh fruits, vegetables, and meats, as well as processed products such as salads and baked goods (Seideman and Durland, 1984; Kader, 1980). The main functions of CAP are to reduce the oxygen concentration and increase the partial pressure of carbon dioxide in food packages. Reduced oxygen levels can reduce the rate of lipid oxidation and the growth of aerobic bacteria. Elevated carbon dioxide pressure can reduce the growth of certain microorganisms (Silliker and Wolfe, 1980; Gill and Tan, 1980; Gill and Penney, 1988; Dixon and Kell, 1989).

Although changing the atmosphere conditions in food packages can be accomplished by mechanical means, such as vacuum packaging and gas-flushing packaging, these methods are not free from problems. For instance, the stress created by the pressure gradient due to vacuum packaging may damage the texture of foods. Gas flushing may allow the establishment of desired atmosphere conditions, however, the cost associated with the facilities and the complexity of the operation often limits its use in food industry.

Compounds that simultaneously absorb oxygen and release carbon dioxide have been formulated for growing anaer obic bacteria in J apan. However, reports regarding the use of these compounds for food packaging was not found in the literature. The main objective of this study was to formulate controlled atmosphere agents using food grade ingredients, which not only can effectively remove oxygen but can also release carbon dioxide in a closed system.

\section{MATERIALS AND METHODS}

Ingredients. Sodium ascorbate (SA) was purchased from Sigma Co. (St. Louis, MO). Sodium bicarbonate (SB), sodium carbonate-10-hydrate (SC), and ferrous sulfate-7-hydrate (FS)

* To whom correspondence should be addressed (telephone 011886-2-2363-2821; fax 011886-2-2362-0849; e-mail bhchiang@ccms.ntu.edu.tw). were purchased from Riedel-de Haen Co. (Seelze, Germany). Calcium carbonate, potassium carbonate, and sodium carbonate were purchased from Hayashi Pure Chemical Industries, Ltd. (Osaka, J apan). SC and FS were ground to reduce their particle sizes to 60-140 and 140-270 mesh, respectively.

Determinations of Oxygen and Carbon Dioxide Concentrations. Predetermined weights of chemicals were put in a $285 \mathrm{~mL}$ flask and sealed with a rubber stopper and a rubber band. The flasks were incubated at $25 \pm 2{ }^{\circ} \mathrm{C}$. At predetermined periods, $0.5 \mathrm{~mL}$ of air within the flasks were sampled by puncturing the rubber stopper with an airtight gas chromatography syringe. Since the pressure in the flask fluctuated during experiment, an airtight syringe was needed to ensure that the pressure did not affect the measurements. The oxygen and the carbon dioxide concentrations of the air samples were analyzed by gas chromatography (model GC320, Gasukurd Kogyo Co., Tokyo, J apan) with a CTR-I col umn (Chiovalley Co., Marietta, $\mathrm{OH}$ ) and a thermal conductive detector (TCD). The temperature for column, detector, and injector was maintained at $30^{\circ} \mathrm{C}$, and helium was used as the carrier gas at $55 \mathrm{~mL} / \mathrm{min}$.

Screening of the Basic Ingredients. The basic ingredients needed for formulating controlled atmosphere agents (CAA) may include reductant and carbonate. Traditional one factor-at-a-time approach was used to screen the critical reductants and carbonates. Several reductants, including SA, iron powder, copper powder, FS, and copper sulfate were tested to determine their ability to serve as reducing agents. The carbonates being tested in this study included sodium carbonate, SC, SB, calcium carbonate, and potassium carbonate.

Experimental Design. Four basic ingredients for formulating the controlled atmosphere agents were selected from the screening procedure mentioned above. To develop the mathematical models giving oxygen and carbon dioxide concentrations as a function of four ingredient variables, an appropriate experimental design was needed to limit the number of experimental points. The Box-Behnken design (1960) for four variables each with three different levels was adopted (Table 1, no. 1-25). All experimental runs were performed in a random order. To establish an effective controlled atmosphere packaging system, it was required that all the developed formulations could enable the atmospheric compositions in a $285 \mathrm{~mL}$ flask to reach equilibrium within $24 \mathrm{~h}$. To satisfy the $24 \mathrm{~h}$ time constraint, a series of experiments based on the Box-Behnken design were performed repeatedly to locate the proper weight range for each ingredient variable. One of the drawbacks of using the Box-Behnken 
Table 1. Oxygen and Carbon Dioxide Concentrations in a $285 \mathrm{~mL}$ Flask Resulted from the Reactions of $\mathbf{4 1}$ Formulations Based on Box-Behnken Design

\begin{tabular}{|c|c|c|c|c|c|c|}
\hline \multirow[b]{2}{*}{ no. } & \multicolumn{4}{|c|}{ coded levels of ingredient variables ${ }^{a}$} & \multirow[b]{2}{*}{$\mathrm{O}_{2}(\%)$} & \multirow[b]{2}{*}{$\mathrm{CO}_{2}(\%)$} \\
\hline & SA & SB & SC & FS & & \\
\hline 1 & 1 & 1 & 0 & 0 & 3.40 & 9.42 \\
\hline 2 & $\overline{1}$ & $-\overline{1}$ & 0 & 0 & 3.30 & 17.10 \\
\hline 3 & -1 & 1 & 0 & 0 & 2.79 & 18.24 \\
\hline \multirow[t]{2}{*}{4} & -1 & -1 & 0 & 0 & 8.23 & 9.34 \\
\hline & -1 & -1 & 0 & 0 & 7.73 & 11.68 \\
\hline 5 & 1 & 0 & 1 & 0 & 5.90 & 1.15 \\
\hline 6 & 1 & 0 & -1 & 0 & 4.13 & 21.98 \\
\hline 7 & -1 & 0 & 1 & 0 & 7.08 & 1.68 \\
\hline 8 & -1 & 0 & -1 & 0 & 3.40 & 33.63 \\
\hline 9 & 1 & 0 & 0 & 1 & 1.86 & 21.07 \\
\hline \multirow[t]{2}{*}{10} & 1 & 0 & 0 & -1 & 5.86 & 0.62 \\
\hline & 1 & 0 & 0 & -1 & 4.93 & 1.40 \\
\hline 11 & $-\overline{1}$ & 0 & 0 & 1 & 1.71 & 36.54 \\
\hline 12 & -1 & 0 & 0 & -1 & 8.80 & 0.96 \\
\hline \multirow[t]{2}{*}{13} & 0 & 1 & 1 & 0 & 6.41 & 1.64 \\
\hline & 0 & 1 & 1 & 0 & 6.15 & 3.54 \\
\hline 14 & 0 & 1 & -1 & 0 & 2.01 & 29.88 \\
\hline 15 & 0 & -1 & 1 & 0 & 8.64 & 0.05 \\
\hline 16 & 0 & -1 & -1 & 0 & 4.22 & 24.34 \\
\hline 17 & 0 & 1 & 0 & 1 & 1.77 & 31.22 \\
\hline 18 & 0 & 1 & 0 & -1 & 4.64 & 0.95 \\
\hline \multirow{2}{*}{19} & 0 & -1 & 0 & 1 & 2.16 & 31.01 \\
\hline & 0 & -1 & 0 & 1 & 6.43 & 22.66 \\
\hline 20 & 0 & -1 & 0 & -1 & 8.92 & 0.83 \\
\hline 21 & 0 & 0 & 1 & 1 & 4.64 & 11.45 \\
\hline 22 & 0 & 0 & 1 & -1 & 6.44 & 0 \\
\hline 23 & 0 & 0 & -1 & 1 & 2.23 & 40.73 \\
\hline 24 & 0 & 0 & -1 & -1 & 4.40 & 9.25 \\
\hline \multirow[t]{4}{*}{25} & 0 & 0 & 0 & 0 & 5.15 & 13.00 \\
\hline & 0 & 0 & 0 & 0 & 5.10 & 12.81 \\
\hline & 0 & 0 & 0 & 0 & 5.05 & 13.81 \\
\hline & 0 & 0 & 0 & 0 & 5.39 & 13.46 \\
\hline 26 & -1 & -1 & -1 & -1 & 9.61 & 5.15 \\
\hline 27 & 1 & -1 & -1 & -1 & 5.72 & 3.29 \\
\hline 28 & -1 & 1 & -1 & -1 & 4.59 & 13.22 \\
\hline 29 & 1 & 1 & -1 & -1 & 5.03 & 5.14 \\
\hline 30 & $-\overline{1}$ & $-\overline{1}$ & 1 & $-\overline{1}$ & 10.99 & 0 \\
\hline 31 & 1 & -1 & 1 & $-\overline{1}$ & 5.32 & 0 \\
\hline 32 & $-\overline{1}$ & 1 & 1 & $-\overline{1}$ & 8.66 & 0.62 \\
\hline 33 & 1 & 1 & 1 & -1 & 4.85 & 0 \\
\hline 34 & -1 & -1 & -1 & 1 & 2.68 & 42.05 \\
\hline 35 & 1 & -1 & -1 & 1 & 3.73 & 32.34 \\
\hline 36 & -1 & 1 & -1 & 1 & 1.50 & 44.73 \\
\hline 37 & 1 & 1 & -1 & 1 & 2.65 & 33.24 \\
\hline 38 & -1 & -1 & 1 & 1 & 6.78 & 12.20 \\
\hline 39 & 1 & -1 & 1 & 1 & 6.15 & 5.40 \\
\hline 40 & -1 & 1 & 1 & 1 & 2.67 & 19.66 \\
\hline 41 & 1 & 1 & 1 & 1 & 4.43 & 4.83 \\
\hline
\end{tabular}

a The actual weights corresponding to the coded levels of each ingredient were a s follows. SA: $-1,0.3 \mathrm{~g} ; 0,0.8 \mathrm{~g} ; 1.1 .3 \mathrm{~g}$. SB: $-1,0.5$ g; $0,1.3$ g; 1, 2.1 g. SC: $-1,2.2$ g; $0,3.0$ g; 1, 3.8 g. FS: -1 , $1.2 \mathrm{~g} ; 0,1.7 \mathrm{~g} ; 1,2.2 \mathrm{~g}$.

design for building a mathematical model is that poor estimations may result in the response values at the extremes, that is, at the points which all ingredient variables are either at their highest or lowest levels. To overcome this problem, 16 extreme points (Table 1, no. 26-41) were then added to increase the estimation power near the extremes.

Model Building and Data Analysis. A stepwise regression procedure in the SAS package (SAS I nstitute, Inc., Cary, NC) was used to fit the oxygen and carbon dioxide data into second-order polynomial equations with the following interaction terms

$$
\mathrm{Y}=\mathrm{B}_{\mathrm{o}}+\mathrm{B}_{\mathrm{i}} \Sigma \mathrm{X}_{\mathrm{i}}+\mathrm{B}_{\mathrm{ii}} \Sigma \mathrm{X}_{\mathrm{i}}^{2}+\mathrm{B}_{\mathrm{ij}} \Sigma \mathrm{X}_{\mathrm{i}} \mathrm{X}_{\mathrm{j}} \quad(\mathrm{i} \neq \mathrm{j})
$$

where $Y$ is the dependent variable (in percentage), $B_{0}, B_{i}, B_{i i}$ $B_{i j}$ are regression coefficients of the model, and $X_{i}$ are quantities (in weight, gram) of each ingredient (subscripts $\mathrm{i}, \mathrm{j}$ $=1,2,3,4$ represent SA, SB, SC, and FS, respectively). An F test for lack of fit was used to determine whether the regression model s adequately fit the experimental data. Once the regression models were developed, 11 new experimental points selected randomly were conducted to test the models.

\section{RESULTS AND DISCUSSION}

Selection of the Basic Ingredients. Sodium ascorbate, iron powder, and copper powder may be the most common reductants for CAA (Stitt and Monthony, 1988; Matsuo et al., 1992). Our preliminary study showed that the efficiencies of iron and copper powders in removing oxygen were lower than that of SA (data not shown). Our data al so showed that the reaction rate of iron and copper powders depended upon the humidity of the air. In general, high humidity caused a faster reaction. J ohnson (1983) stated that the addition of water may be needed to start the oxidation of CAA containing iron powder. Since SA showed high efficiency in removing oxygen and independence to the humidity and it is a food grade ingredient, we decided to formulate CAA using SA as the reductant. The preliminary study also showed that FS and copper sulfate could improve the performance of SA type CAA. Although copper sulfate exhibited higher efficiency than FS, copper sulfate was not included in the formulation mainly because it is not a food grade additive. Due to its ability to perform oxidation reaction and/or to accelerate the oxidation reaction of SA, FS was included in the formulations. The mechanisms of the oxidation of SA and FS are shown bel ow:

$$
\begin{gathered}
\mathrm{C}_{6} \mathrm{H}_{7} \mathrm{O}_{6} \mathrm{Na} \text { (sodium ascorbate) }+\mathrm{O}_{2} \rightarrow \\
\mathrm{C}_{2} \mathrm{H}_{2} \mathrm{O}_{4} \text { (oxalic acid) }+\mathrm{C}_{4} \mathrm{H}_{7} \mathrm{O}_{5} \\
4 \mathrm{FeSO}_{4} \cdot 7 \mathrm{H}_{2} \mathrm{O} \rightarrow 4 \mathrm{Fe}^{2+}+4 \mathrm{SO}_{4}{ }^{2-} \\
4 \mathrm{Fe}^{2+}+\mathrm{O}_{2}+10 \mathrm{H}_{2} \mathrm{O} \rightarrow 4 \mathrm{Fe}(\mathrm{OH})_{3}+8 \mathrm{H}^{+}
\end{gathered}
$$

The acids in the forms of oxalic acid and hydrogen ion yiel ded from the above reactions could further react with carbonate to produce carbon dioxide. Several carbonates, including sodium carbonate, SC, SB, calci um carbonate, and potassium carbonate were tested to determine their abilities in producing carbon dioxide in almost anhydrous condition. Our preliminary results (data not shown) indicated that all the tested carbonates could not initiate the release of carbon dioxide, except SB presented some activity at high-humidity conditions. The mechanisms of the reactions between SB and the acid components produced from the oxidation are shown below:

$$
\begin{gathered}
\mathrm{C}_{2} \mathrm{H}_{2} \mathrm{O}_{4} \text { (oxalic acid) }+2 \mathrm{HCO}_{3}{ }^{-} \rightarrow \\
\left(\mathrm{COO}^{-}\right)_{2}{ }^{2-}+2 \mathrm{H}_{2} \mathrm{O}+2 \mathrm{CO}_{2} \\
8 \mathrm{H}^{+}+8 \mathrm{HCO}_{3}{ }^{-} \rightarrow 8 \mathrm{CO}_{2}+8 \mathrm{H}_{2} \mathrm{O}
\end{gathered}
$$

However, when SC was included in the formulation, the rate of release of carbon dioxide from SB increased dramatically. This may be explained by the following reasons: (1) the support of water molecules from SC improved the rate of chemical reaction and (2) SC provided alkaline conditions that enhanced the initial rate of the oxidation reaction of SA. Ther efore, both SB and SC were included as the basic ingredients for a total sum of four ingredients in our formulations. The effect 
Table 2. Regression Coefficients of the Models Representing the Oxygen and Carbon Dioxide Concentrations in a $\mathbf{2 8 5} \mathbf{~ m L}$ Flask ${ }^{\mathrm{a}}$

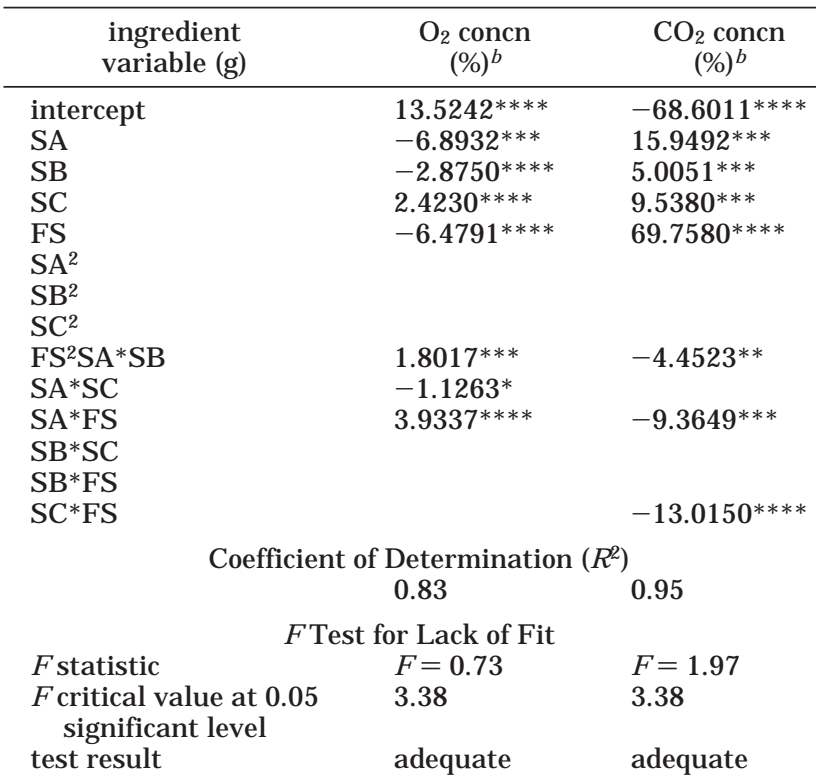

a The linear effects were forced into the models. ${ }^{b}$ Regression coefficient significant at the $(*) 0.15$ level $(* *) 0.05$ level $(* * *) 0.01$ level, and (****) at 0.001 level.

of humidity was further examined by testing three combinations of the four selected ingredients at three relative humidities $(52 \%, 75 \%$, and $98 \%)$. It was found that humi dity affected neither the rate of the reactions nor the final levels of oxygen and carbon dioxide in the system. The result of this preliminary study suggested that SC and FS in the formulations contained enough water (in crystal form) for carrying out the reactions al ready. Ther efore, humidity was not considered as a variable for the subsequent experiments.

Regression Models of Oxygen and Carbon Dioxide. A series of experiments based on Box-Behnken design were performed repeatedly in order to search for formulations which could enable the atmospheric compositions in a $285 \mathrm{~mL}$ flask to reach equilibrium within $24 \mathrm{~h}$. Our main goal was to develop effective formulations that would remove oxygen and release carbon dioxide simultaneously. In this study, we considered 24 $\mathrm{h}$ to be a reasonable time constraint for evaluating the performance of the formulations. Only the results of the final run of the Box-Behnken design are shown in Table 1 (no. 1-25). The second-order polynomial regression models of the oxygen and the carbon dioxide contents based on the results obtained from the 25 experimental points showed that all quadratic terms of the models were not significant $(p>0.05)$, indicating the lack of curvature of the models. In this case, the optimal responses (maximum or minimum response) predicted by the models are often the response values at the extremes (experimental boundaries) of ingredient variables. Myers and Montgomery (1995) reported that the use of Box-Behnken design should be confined to situations in which one is not interested in predicting response at the extremes. Therefore, 16 extreme points (no. 26-41) were added to improve the estimation power near the extremes. Table 2 shows the regression coefficients of the best-fitted regression models giving the oxygen and carbon dioxide concentrations as the function of the ingredient variables. The coefficient of determination $\left(R^{2}\right)$ of oxygen and carbon dioxide models was
Table 3. Verification of the Predictive Capabilities of the Regression Models for Predicting the Oxygen and Carbon Dioxide Concentrations in a 285 mL Flask

\begin{tabular}{|c|c|c|c|c|c|c|c|}
\hline \multicolumn{4}{|c|}{ formulations } & \multicolumn{2}{|c|}{$\mathrm{O}_{2}$ conch $(\%)$} & \multicolumn{2}{|c|}{$\mathrm{CO}_{2}$ conch $(\%)$} \\
\hline SA (g) & SB (g) & $\mathrm{SC}(\mathrm{g})$ & FS (g) & esti.a & $\overline{\text { exp. }^{b}}$ & esti.c & $\exp ^{b}$ \\
\hline 0.9 & 1.4 & 3.5 & 1.9 & 4.9 & 6.2 & 10.5 & 11.8 \\
\hline 0.4 & 0.9 & 3.0 & 1.5 & 7.4 & 8.7 & 9.7 & 8.3 \\
\hline 1.2 & 1.3 & 3.8 & 1.7 & 5.4 & 7.2 & 1.8 & 1.0 \\
\hline 0.7 & 0.6 & 2.5 & 1.3 & 7.0 & 8.2 & 7.4 & 9.3 \\
\hline 0.5 & 1.8 & 2.8 & 2.1 & 2.3 & 2.8 & 31.2 & 29.3 \\
\hline 1.3 & 2.1 & 3.8 & 1.2 & 5.4 & 4.9 & -3.5 & 0 \\
\hline 0.8 & 1.2 & 2.3 & 1.8 & 3.8 & 4.1 & 26.0 & 29.3 \\
\hline 1.1 & 0.6 & 3.3 & 1.3 & 6.5 & 6.0 & 1.9 & 2.0 \\
\hline 1.3 & 1.0 & 3.6 & 1.5 & 5.4 & 6.2 & 1.8 & 1.5 \\
\hline 0.6 & 2.0 & 2.9 & 1.6 & 4.3 & 4.3 & 15.5 & 18.7 \\
\hline 0.7 & 1.5 & 2.6 & 1.2 & 6.1 & 4.1 & 5.4 & 7.5 \\
\hline \multicolumn{8}{|c|}{$\begin{array}{c}\text { Correlation Coefficient between Estimated Values } \\
\text { and Experimental Values }\end{array}$} \\
\hline \multicolumn{4}{|c|}{$\mathrm{O}_{2}$} & \multicolumn{4}{|c|}{$\mathrm{CO}_{2}$} \\
\hline$r=$ & 81 & & & & & & \\
\hline
\end{tabular}

a Estimated value based on the equation of the oxygen content given in Table 2. ${ }^{\mathrm{b}} \mathrm{New}$ experimental values. ${ }^{\mathrm{C}}$ Estimated value based on the equation of the carbon dioxide content given in Table 2.

Table 4. Effect of Each Ingredient Variable on the Concentration of the Oxygen and Carbon Dioxide

\begin{tabular}{|c|c|c|}
\hline ingredient & $\mathrm{O}_{2}$ conch $(\%)$ & $\mathrm{CO}_{2}$ concn (\%) \\
\hline SA & $\begin{array}{l}\text { decrease (at low levels }^{a} \\
\text { of SB and FS) } \\
\text { increase }{ }^{b} \text { (at high levels } \\
\text { of SB and FS) }\end{array}$ & $\begin{array}{l}\text { increase (at low levels } \\
\text { of SB and FS) } \\
\text { decrease(at high levels } \\
\text { of SB and FS) }\end{array}$ \\
\hline SB & decrease & $\begin{array}{l}\text { increase (at low levels } \\
\text { of SA) } \\
\text { decrease (at high levels } \\
\text { of SA) }\end{array}$ \\
\hline $\begin{array}{l}\text { SC } \\
\text { FS }\end{array}$ & $\begin{array}{l}\text { increase } \\
\text { decrease }\end{array}$ & $\begin{array}{l}\text { decrease } \\
\text { increase }\end{array}$ \\
\hline
\end{tabular}

a The corresponding column response decreased with the increase of the corresponding raw ingredient variable. ${ }^{b}$ The corre sponding column response increased with the increase of the corresponding raw ingredient variable.

0.83 and 0.95 , respectively, indicating a good fit of the models. A test of lack of fit showed that both of the models adequately fitted the experimental data (Table 2). To examine the predictive capabilities of the two regression models, 11 separate experiments using randomly selected variables were carried out, and the results are given in Table 3. Since the predicted values based on the regression models were reasonably close to the experimental values, the model s were considered to be useful in predicting the relationships between the ingredient variables and the concentrations of oxygen and carbon dioxide in the packages.

Effects of Ingredients on Oxygen Concentration. All formulations caused a significant reduction of the oxygen content in a $285 \mathrm{~mL}$ flask within $24 \mathrm{~h}$ (Table 1). Since there were four components in our formulations, it was difficult to present their effects on the gas levels graphically. For further interpretation of the data, the models shown in Table 2 were partially differentiated (Table 4). An analysis of the first-ordered partial derivative models for oxygen content showed that FS was the dominant ingredient affecting the oxygen content, followed by SA. This was expected because both FS and SA served as reductants in the formulations to initiate the oxidation process. Regardless of the levels of other ingredient variables, increased FS decreased oxygen 


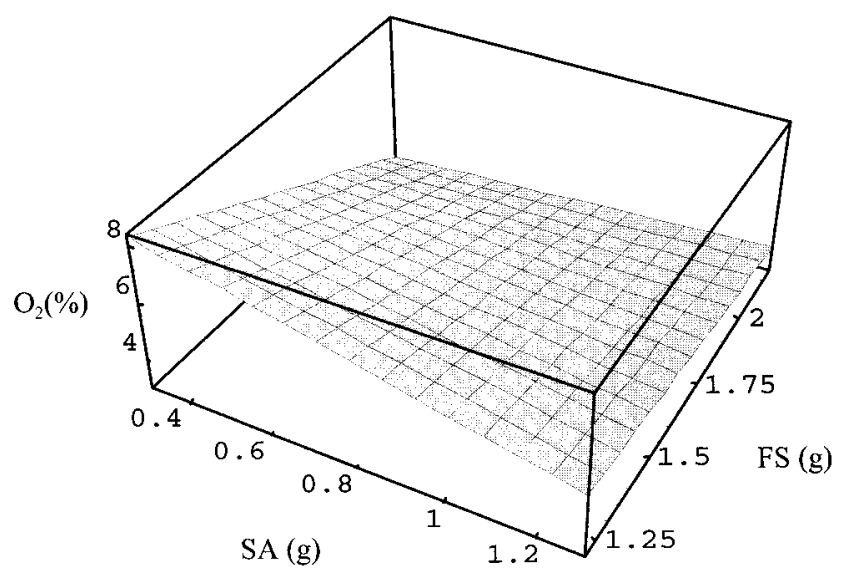

Figure 1. Effects of sodium ascorbate (SA) and ferrous sulfate-7-hydrate (FS) on the oxygen content in a $285 \mathrm{~mL}$ flask at the central level of sodium bicarbonate (SB) and sodium carbonate-10-hydrate (SC) (1.3 and $3.0 \mathrm{~g}$, respectively).

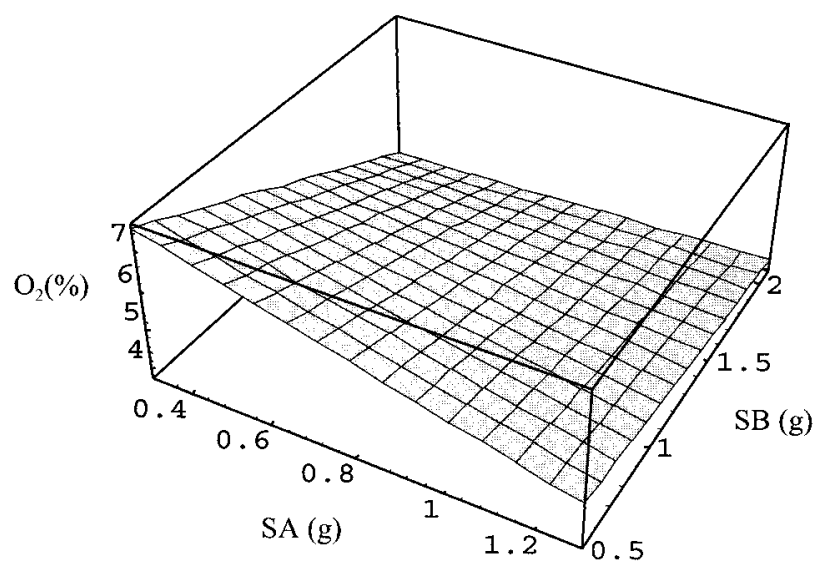

Figure 2. Effects of sodium ascorbate (SA) and sodium bicarbonate (SB) on the oxygen content in a $285 \mathrm{~mL}$ flask at the central level of sodium carbonate-10-hydrate (SC) and ferrous sulfate-7-hydrate (FS) (3.0 and $1.7 \mathrm{~g}$, respectively).

content (Table 4). However, the effect of SA on the oxygen content depended upon the levels of SB and FS in the formulations (Table 2). In general, at low levels of SB and FS, the increase of SA caused a reduction of the oxygen content, while a slight increase of the oxygen content was found by raising the level of SA at either high SB or FS concentration (Figures 1 and 2, generated from the mathematical models shown in Table 2). We assume that the interaction between SA and SB was caused by SB which could provide an alkaline condition required for the oxidation of SA at the initial stage of the oxidation. However, as the oxidation process continued, SB would react with the acid components produced from the oxidation of SA and FS to form carbon dioxide and could no longer provide the alkaline condition for SA. The influences of SB and SC on the oxygen content were lower than those of SA and FS. Raising the level of SB caused a decrease in the oxygen concentration, while increasing the SC content in the formulation tended to increase the oxygen content.

Effects of Ingredients on Carbon Dioxide Concentration. As shown in Table 1, the final carbon dioxide contents of the tested formulations ranged from 0 to $41 \%$. Among the ingredients used in this study, FS was the governing ingredient that affected the concentration of carbon dioxide, followed by SA and SC (Table

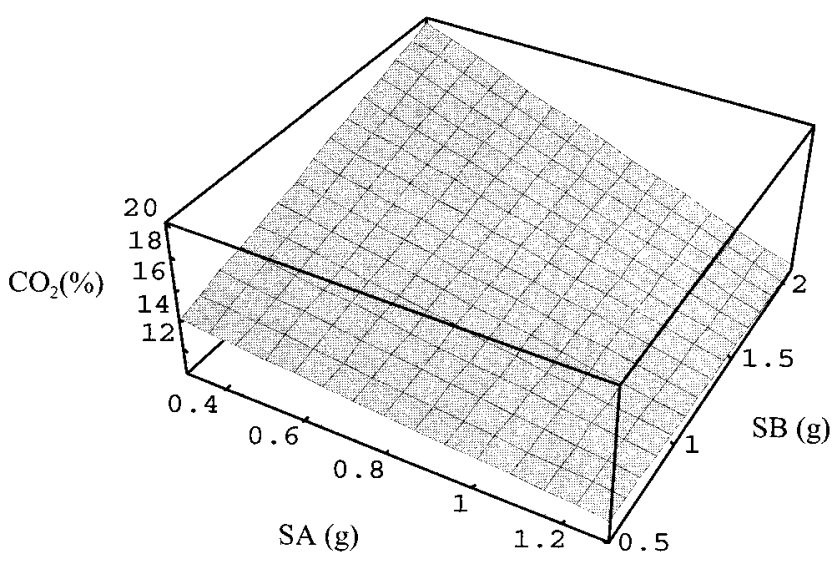

Figure 3. Effects of sodium ascorbate (SA) and sodium bicarbonate (SB) on the carbon dioxide content in a $285 \mathrm{~mL}$ flask at the central level of sodium carbonate-10-hydrate (SC) and ferrous sulfate-7-hydrate (FS) (3.0 and $1.7 \mathrm{~g}$, respectively).

2). Increasing the FS content increased the concentration of carbon dioxide significantly. As mentioned before, FS significantly reduced the oxygen content because it performs an oxidation reaction and catalyzes the oxidation of SA. Since the consumption of oxygen through the oxidation and the subsequent rel ease of carbon dioxide were chain reactions, the effect of FS on the concentration of carbon dioxide was due to its influences on the oxidation process. Similar to the effect of SA on the concentration of the oxygen, the effect of SA on the concentration of the carbon dioxide also depended upon the levels of SB and FS. Raising the level of SA at low levels of SB and FS increased the carbon dioxide concentration. However, reverse outcomes were observed at high SB or FS level (Table 4). Like FS, the influence of SA on the concentration of carbon dioxide might be due to its behavior in the oxidation process. Therefore, the role of the reductant in CAA cannot be overemphasized. A proper sel ection of the reductant appears to be the first step to devel op desired CAA because it affects not only the rate of oxidation but also the extent of the release of carbon dioxide.

The effect of SB on the concentration of carbon dioxide depended on the amount of SA in the formulations. At low SA levels, the increase of SB resulted in an increase of the concentration of carbon dioxide, while reverse results were obtained at a high SA level (Figure 3). We postulated that SB could provide the alkaline condition required for the oxidation of SA, thus, an increase in the rate of oxidation followed by the increase of the concentration of carbon dioxide. However, as the oxidation reaction proceeded, particularly at high SA content, SB could react with hydrogen ion, a product of the oxidation process, to form carbon dioxide. Thus, SB was no longer available for providing the alkal ine condition for the oxidation of SA. SC dramatically decreased the concentration of carbon dioxide. In aqueous solution, SC produced carbonate ion, $\mathrm{CO}_{3}{ }^{2-}$, a base which had strong tendency to react with the oxidative product, hydrogen ion, $\mathrm{H}^{+}$, to form hydrogen carbonate ion, $\mathrm{HCO}_{3}{ }^{-}$. Thus, hydrogen ion (the oxidative product) was no longer available for reacting with the carbonates (SB and SC) to produce carbon dioxide. Therefore, a reduction of the concentration of carbon dioxide was observed when the formulations contained a high amount of SC. 


\section{CONCLUSION}

The controlled atmosphere agent consisting of sodium ascorbate, sodium bicarbonate, sodium carbonate-10hydrate, and ferrous sulfate-7-hydrate was able to effectively remove oxygen and release carbon dioxide. All ingredients used in this study were food grade additives; therefore, the formulations based on these ingredients were considered to be safe for food packaging. The positive effects of controlled atmosphere packaging on improving the storage stability of various food products have been demonstrated by many researches, and the result of this study showed that the required atmosphere conditions for various fruits and vegetables could be generated by a properly designed controlled atmosphere agent. F or future study, however, it would be desirable to conduct experiments for evaluating our formulation using a real food system. Since the preparation of controlled atmosphere agents based on our formulations is quite easy and the ingredient costs are inexpensive, their potential uses for food packaging appeared to be promising. Because the initiation of the reaction of our formulations requires the presence of oxygen, the controlled atmosphere agents could be preserved by vacuum package before uses.

\section{LITERATURE CITED}

Box, G. E. P.; Behnken, D. W. Some new three level designs for the study of quantitative variables. Technometrics 1960, $2,455$.
Brecht, P. E. Use of control led atmospheres to retard deterioration of produce. Food Technol. 1980, 34, 45.

Dixon, K. N.; Kell, D. B. The inhibition by $\mathrm{CO}_{2}$ of the growth and metabolism of microorganisms. J . Appl. Bacteriol . 1989, 67, 109.

Gill, C. O.; Penney, N. The effect of the initial gas vol ume to meat weight ratio on the storage life of chilled beef packaged under carbon dioxide. Meat Sci. 1988, 22, 53.

Gill, C. O.; Tan, K. H. Effect of carbon dioxide on growth of meat spoilage bacteria. Appl. Environ. Microbiol. 1980, 38, 317.

Grau, F. H. Microbial growth on fat and lean surfaces of vacuum-packaged chilled beef. J . Food Sci. 1983, 48, 326.

J ohnson, R. Generation of microaerophilic atmosphere. U.S. patent 4377554, March 22, 1983.

Kader, A. A. Prevention of ripening in fruits by use of controlled atmospheres. Food Technol. 1980, 34, 51.

Matsuo, R.; Saisho, K.; Maruta, J . Atmosphere conditioning agent. WO92/15398, September 17, 1992.

Myers, R. H.; Montgomery, D. C. In Response Surface Methedology; J ohn Wiley \& Sons: New York, 1995.

Seideman, S. C.; Durland, P. R. The utilization of modified gas atmosphere packaging for fresh meat: a review. J . Food Qual. 1984, 6, 239.

Silliker, J. H.; Wolfe, S. K. Microbiological safety considerations in controlled atmosphere storage of meats. Food Technol. 1980, 34, 59.

Stitt, D. T.; Monthony, J . F . Method for modifying a contained gaseous mixture. European patent 0290781, November 17, 1988.

Received for review J uly 16, 1998. Accepted December 21, 1998.

J F 980770I 